\title{
Passenger AIR-BAG Status Indication Awareness Study
}

Reprint from SAE Technical Paper Series, SP 1242 , paper 970276, pp 47-55 (International Congress \& Exposition, Detroit, USA, February 24-27, 1997)

Malin Henriksson, Anders Hallén, Mats Höwing and Björn Lundell, Volvo Car Corporation

Martin Ericson, SAAB Automobile $A B$

Lena Nilsson and Maria Berlin, VTI

PASSENGER AIRBAG

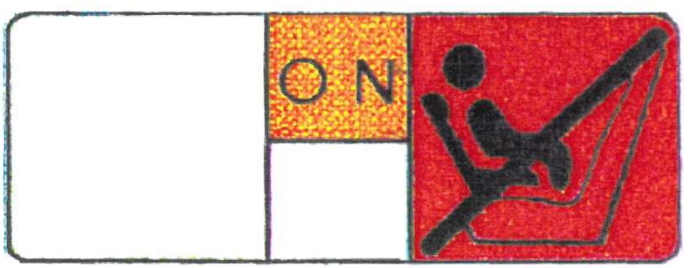

PASSENGER AIRBAG

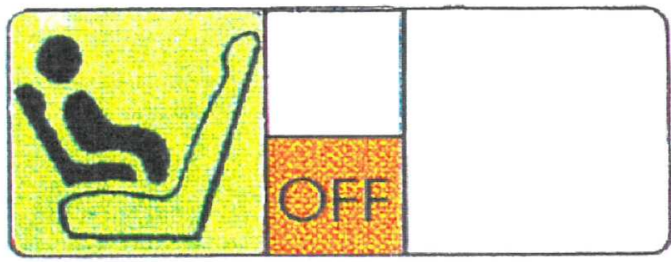

a. 


\section{VTI särtryck 295 · 1998 \\ Passenger AIR-BAG Status Indication Awareness Study}

Reprint from SAE Technical Paper Series, SP 1242, paper 970276, pp 47-55 (International Congress \& Exposition, Detroit, USA, February 24-27, 1997)

Malin Henriksson, Anders Hallén, Mats Höwing and Björn Lundell, Volvo Car Corporation Martin Ericson, SAAB Automobile $A B$ Lena Nilsson and Maria Berlin, VTI 

SAE TECHNICAL PAPER SERIES

\section{Passenger AIR-BAG Status Indication Awareness Study}

Malin Henriksson, Anders Hallén, Mats Höwing, and Björn Lundell

Volvo Car Corporation

Martin Ericson

SAAB Automobile $A B$

Lena Nilsson and Maria Berlin Swedish National Road and Transport Research Institute

Reprinted from: Progress with Human Factors in Automotive Design:

Seating Comfort, Visibility, and Safety

(SP-1242) 
he appearance of the ISSN codeat the bottom of this page indicates SAE's consent that copies of the papermaybe madeforpersonal orintemal use of specificclients. This consent is given on the condition however, that the copierpay a $\$ 7.00$ per article copy fee through the Copyright Clearance Center, Inc. Operations Center, 222 Rosewood Drive, Danvers, MA 01923 for copying beyond that permitted by Sections 107 or 108 of the U.S. Copyright Law. This consent does not extend to otherkinds of copying such as copying for general distribution, for advertising orpromotional purposes, forcreating new collective works, or forresale.

SAE routinely stocks printed papers for a period of three years following date of publication. Direct your orders to SAE Customer Sales and Satisfaction Department.

Quantity reprint rates can be obtainedfrom the Customer Sales and Satisfaction Department.

To requestpermission to reprint a technical paperorpermission to use copyrighted SAE publications in otherworks, contact the SAEPublications Group.

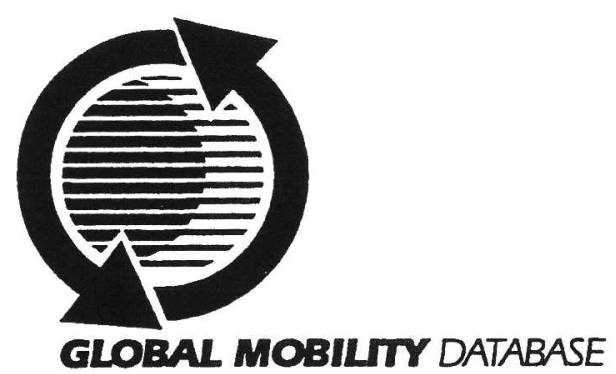

All SAE papers, standards, and selected books are abstractedand indexed in the SAE GlobalMobility Database.

Nopart of this publication may by reproduced in any form, in an electronic retrieval system or otherwise, without the priorwritten permission of the publisher.

\section{ISSN0148-7191}

Copyright 1997 Society of Automotive Engineers, Inc.

Positionsand opinionsadvanced in this paper arethose of the author(s) and not necessarily those of SAE. The author is solely responsible for the content of the paper. A process is available by which discussions will be printed with the paper if it is published in SAE Transactions. For permission to publish this paper in full or in part, contact the SAE Publications Group.

Personswishing to submitpapers to be considered forpresentation or publication through SAE should send the manuscript or a 300 word abstract of a proposed manuscript to: Secretary, Engineering Meetings Board, SAE.

\section{Printedin USA}




\title{
Passenger AIR-BAG Status Indication Awareness Study
}

\author{
Malin Henriksson, Anders Hallén, Mats Höwing, and Björn Lundell \\ Volvo Car Corporation \\ Martin Ericson \\ SAAB Automobile AB \\ Lena Nilsson and Maria Berlin \\ Swedish National Road and Transport Research Institute
}

Copyright 1997 Society of Automotive Engineers, Inc.

\section{ABSTRACT}

With the growing concern about the potential dangers with rear facing child seats placed in the front seat of passenger airbag equipped cars, various systems are being considered for deactivation of the airbag.

To increase the awareness of and confidence in these proposed systems, information displays were developed for the purpose of telling the status of the passenger airbag system and to warn when necessary. A study of the effectiveness, understanding and acceptance of a selection of such information displays was jointly undertaken by Volvo Car Corporation, $\mathrm{SAAB}$ Automobile $\mathrm{AB}$ and the Swedish National Road and Transport Research Institute.

Respondents of various age and demographic composition, parents and grand parents of small children, were exposed to six different sets of information displays and were asked to interpret them and also rank which information displays that would most clearly convey the message. Conclusions were drawn concerning information content, symbols and colours.

The study did also investigate the respondents preference regarding automatic or manual disconnection airbag system.

\section{INTRODUCTION}

\section{Identified problem}

Industry, government and independent organisations are strongly addressing the issue of preventing deployment of airbags when children or children in child seats, in particular rear facing child seats, are placed on the front passenger seat. The extreme force from the deploying airbag, hitting a rear facing child seat would in most cases result in the child being seriously injured or even killed. Children facing forward are also exposed to potential injury but the danger is not as extreme as with rear facing child seats.

This study focuses mainly on how to communicate the considerations of placing a small child in a rear facing child seat in the front passenger seat of a car equipped with a passenger airbag.

\section{Airbag disconnection system}

A number of technical solutions are being developed which aim at detecting the presence of a small passenger, a child or a rear facing child seat in the front passenger seat in order to disconnect the passenger airbag.

This study does not deal with the technical solutions in detail but there are general questions included in the clinic regarding the attitude towards an automatic system versus a manual system. 


\section{The need for an indication display}

Whether an automatic or manual system, an indication display would be beneficial for the driver (parent) to be able to monitor the airbag status. The reasons for this are:

- to inform the car occupants that there is a disconnection system in the car

- to inform the car occupants if the airbag is switched ON or OFF

- to verify airbag status in a manual system.

- to reduce the risks of a driver being unaware of a dangerous situation considering the type of occupant in the front passenger seat

- to increase the user's confidence in an automatic system

\section{The purpose of the clinic}

The clinic's primary aim was to find an appropriate structure and information content of an indication display in order to communicate potentially dangerous situations regarding small children in combination with passenger airbag.

In order to increase the understanding of the indication display, it would help the users if a similar indication display is used by all car manufacturers. With this purpose in mind, several parties were invited to participate.Even though the clinic was performed in Sweden, information has continuously been provided to other car manufacturers.

\section{THE CLINIC STUDY}

\subsection{Method of clinic}

In order to include many interviewees in the study, a paper and pencil clinic was prepared. Altogether there were 99 respondents involved.

\section{The structure of the questionnaire}

The introductory part consisted of questions regarding the interviewees background and their knowledge about airbags.

The essential part of the questionnaire, where the interviewees were interpreting the different display alternatives, was based on both 'open' and multiple choice questions. The open questions, where the interviewees should answer by their own words, were followed by multiple choice questions with alternative but fixed answers.

The questionnaire was based on a 'within subject design' which means that each interviewee was confronted to all display alternatives. Each display alternative was presented on its own page. In order to avoid effects of learning it was nec essary to vary the order of presentation of the alternatives.

The last part of the questionnaire dealt with the interviewees attitude towards automatic versus manual airbag disconnection systems. Furthermore the interviewees were asked how they would prefer the lighting of the display.

\section{Procedure}

SAAB Automobile AB, VTI (Swedish National Road and Transport Research Institute) and Volvo Car Corporation have each carried out this clinic with 33 respondents involved. Totally 99 persons have completed the questionnaire.

The respondents were not selected on a statistical basis but mainly gathered from personal contacts.

The questionnaire was distributed to the respondents either by mail or by a personal hand over. The questionnaire included thorough instructions on how to answer the questionnaire, emphasising that the respondent had to answer the questions in the order they appeared and not to discuss the answers with anyone while completing the questionnaire.

The summary of results from the questionnaire were put together at the three different sites and sent back to Volvo. The analysis has mainly been carried out at Volvo.

\section{Target group}

The target group consisted of car drivers that were either parents or grandparents to children, 0 to 5 years. Elder sisters or brothers were also included in the statistics.

In order to avoid biased opinions the respondents were selected from outside the car industry.

The definition of a car driver was that the interviewee had to have a driving license. There was no differentiation between being parent or grandparent in the analysis.

The demographics of the respondents are shown in the following Figures $1-4$. 
Figure 1 The respondents' sex and age

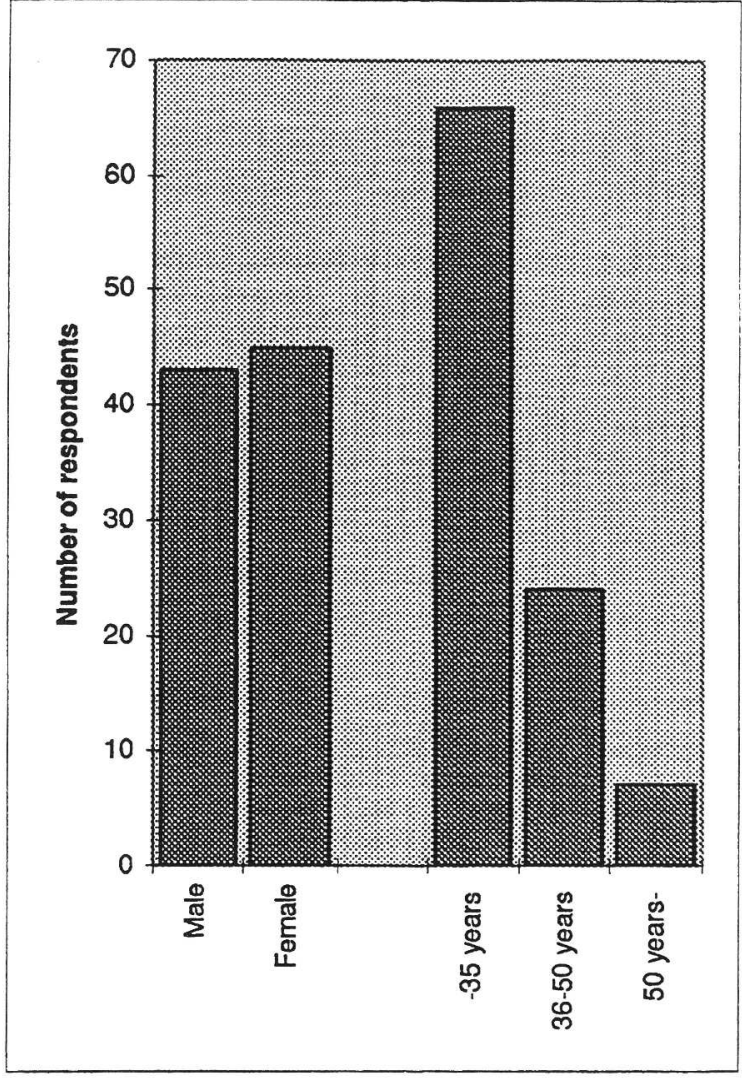

Figure 2 The children's age

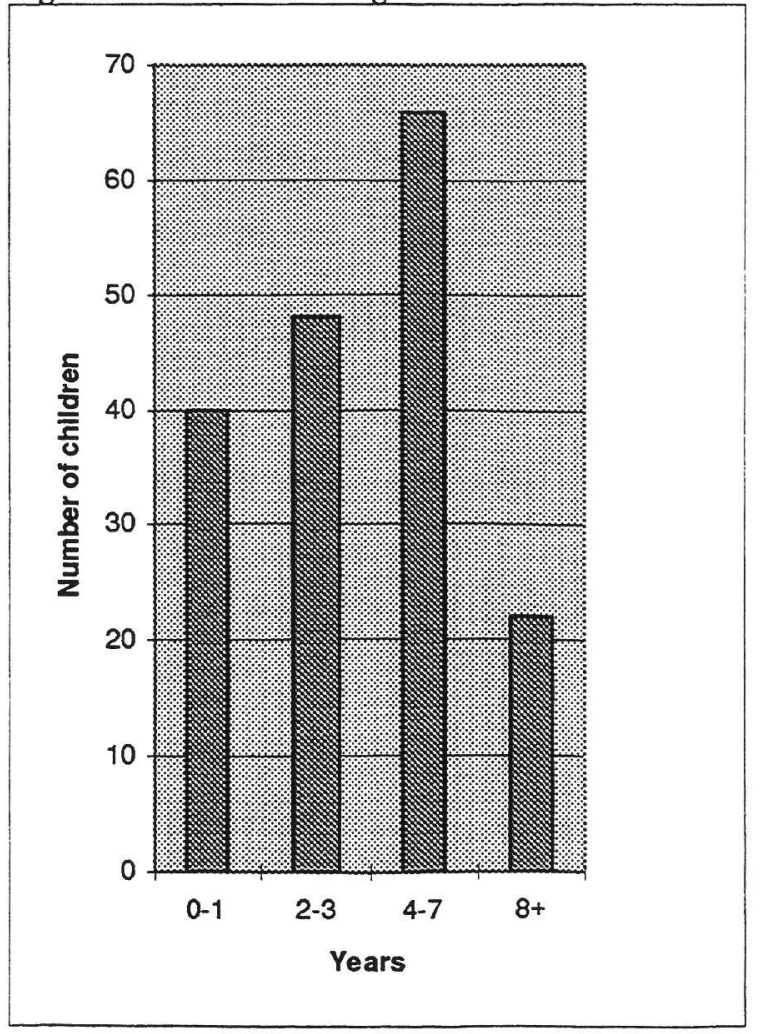

Figure 3 The placement of the children

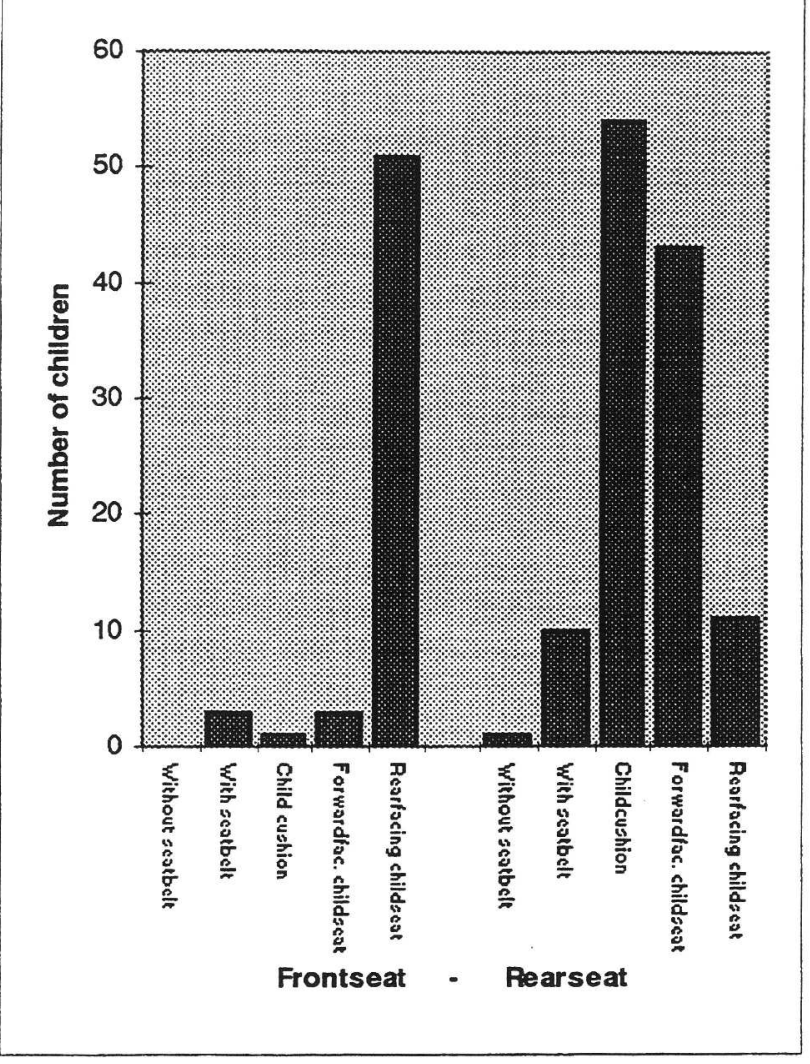

Figure 4 Experience of airbag

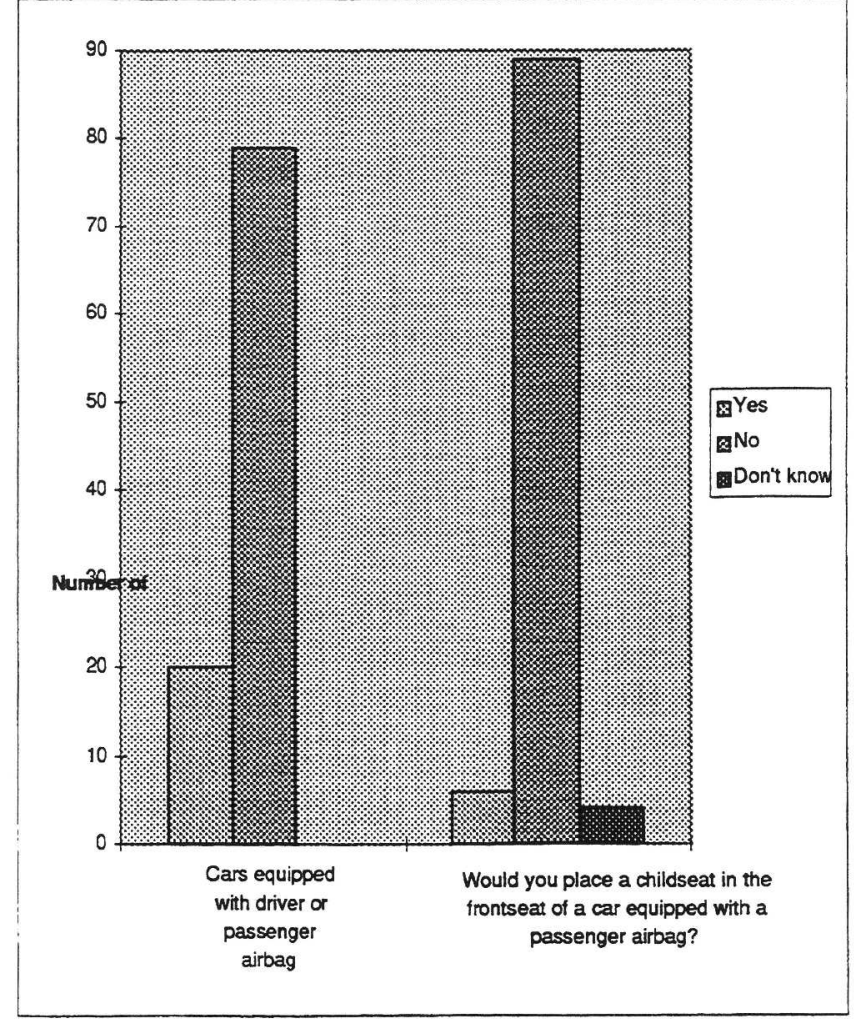




\subsection{Display alternatives}

\section{The graphical layout}

The graphical design is of a principal nature and should be judged by their information content and not by its "design". The symbol indicating "passenger airbag" is the ISOsymbol (7000-2108). The symbol indicating a rear facing child seat placed in the front passenger seat derives from warning labels being proposed for standardisation by ISO.

The clinic does not test how large the display ought to be or where it should be located in the vehicle, even though these factors are of main importance when choosing a realistic alternative. It should be mentioned that the size of the displays in the paper clinic are rather large compared to a realistic size in a vehicle. Furthermore the clinic does not take into account how the display would be manufactured technically.

After a series of meetings between $\mathrm{SAAB}$ Automobile AB, VTI (Swedish National Road and Transport Research Institute) and Volvo Car Corporation six display alternatives were chosen. The reason for the different design principles is that alternative 1-3 and 5-6 were developed at Volvo and alternative 4 at SAAB. Altogether there were eleven displays alternatives to interpret.

\section{Discussion of principles of information presentation}

- Text - Symbol

Should the display be based on only text, or only symbols, or a combination of both?

- Child - Adult

How much information should be included? Should the information concern the child or the adult passenger or a combination of both?

- OK - Warning

Should the display show the dangerous situation, or communicate the safe situation, or both, or be situation neutral?

- Colours

What colours should be used and why?

According to ISO standard 2575, "Road Vehicles Symbols for controls, indicators and tell-tales", the colours have the meaning indicated:

RED: Danger to person or very serious damage immediate or imminent

YELLOW or AMBER: caution, outside normal operating limits, vehicle system malfunction, damage to vehicle likely, or other condition which may produce hazard in the long term.

GREEN: safe, normal operating condition

\section{- Actions}

Should the display tell the car occupant what to do if the passenger airbag is connected? Implicit or explicit?
None of the displays does explicitly inform about exact actions to be taken, due to increased complexity.

Note!

The following display alternatives are based on colours which unfortunately cannot be printed in this paper. The colours used are indicated below each display. In the study, the respondents were exposed to coloured display alternatives.

\section{Alternative 1}

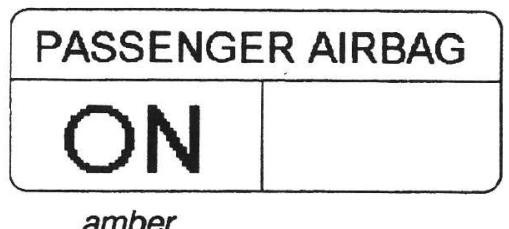

amber

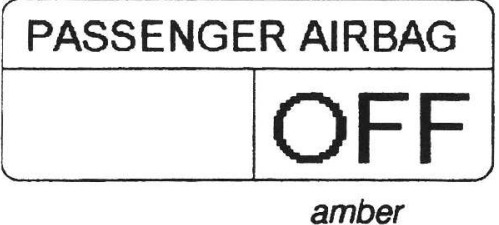

- Text only

- No specific information regarding child or adult passenger

- Does not communicate whether the situation is safe or not

- Amber colour means that the driver should be aware of the situation.

\section{Alternative 2}
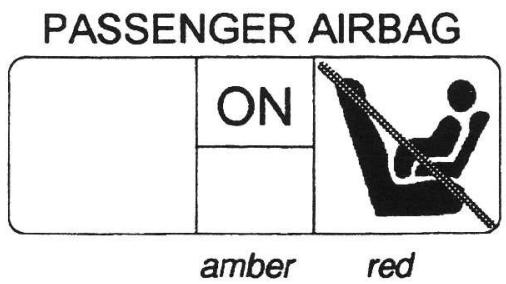

\section{PASSENGER AIRBAG}

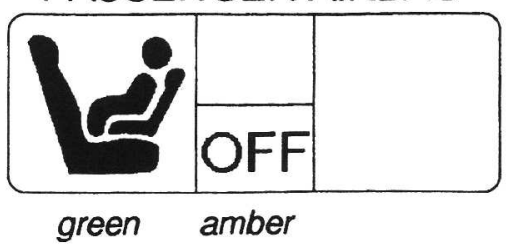

- Symbol and text

- The display focuses on the child

- Both the dangerous situation and the safe situation for a child in a rear facing child seat is communicated

- To illustrate the dangerous situation the colour red is used in combination with a slash. The reason to not use a cross is that the symbol would become very cluttered. The safe situation is communicated with a green colour. 
Alternative 3

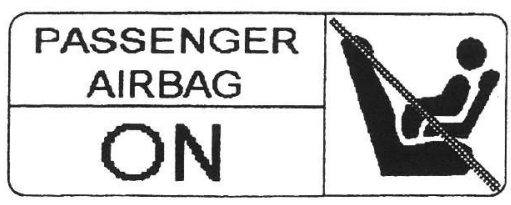

amber

red

- Symbol and text

- The display focuses on the child

- Only the dangerous situation is communicated. It does not at all display the situation when the airbag is disconnected.

- To illustrate a dangerous situation the colour red is used in combination with a slash. The reason to not use a cross is that the symbol would become very cluttered.

\section{Alternative 4}

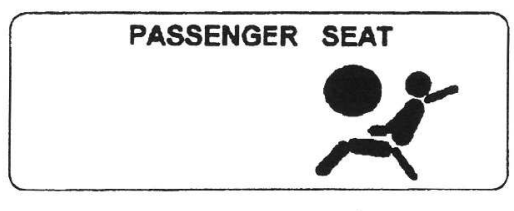

amber

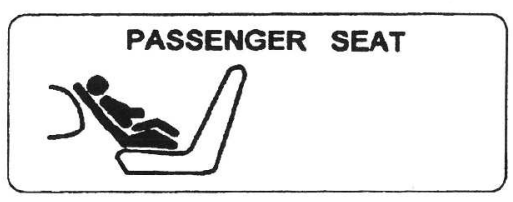

amber

- Symbol and text

- The display does take into account both the adult passenger as well as the child.

- The display does not warn, it only shows what should be placed in the front seat. It does not include any text telling whether the airbag is connected or not.

- Amber colour means that the driver should be aware of the situation.

\section{Alternative 5}

\section{PASSENGER AIRBAG}

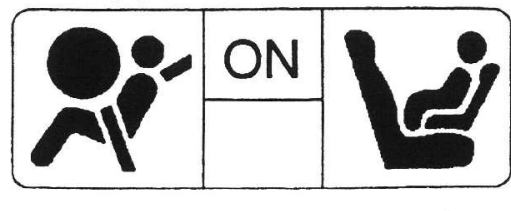

green amber red

\section{PASSENGER AIRBAG}

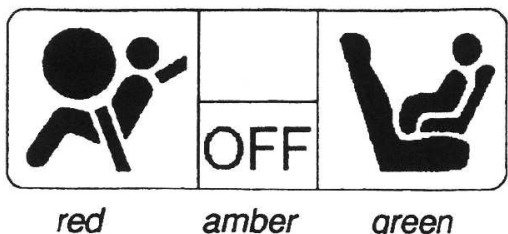

- Symbols and text
- The display shows simultaneously the situation for both potential passenger and child

- The situations shown are both the safe and unsafe situations

- The unsafe/dangerous situation is communicated through a red colour and do not make use of a slash. The safe situation is communicated through a green colour.

\section{Alternative 6}

\section{PASSENGER AIRBAG}

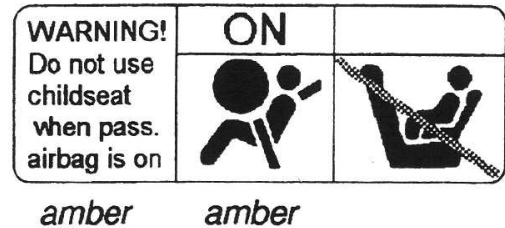

\section{PASSENGER AIRBAG}

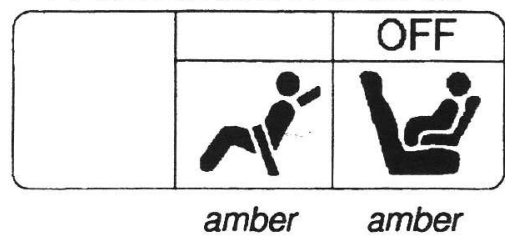

- Symbols and text.

- The display shows simultaneously the situation for both the passenger and the child

- The situations shown are both the safe and unsafe situations

- The unsafe/dangerous situation for the child is communicated through a red slash. The potential unsafe/dangerous situation for grown up passenger is communicated through a modified ISO airbag symbol. 


\subsection{Results from clinic}

\section{Figure 5 - Order of preference}

This figure shows in what order of priority the respondents placed the display alternatives.

"13. Which one of the display alternatives that you been through do you think shows enough information to judge whether the situation is safe or not?"

The ranking number 1 means that the respondent found that display alternative the best. The display alternative that has the largest share of light shades did get the highest mark.

\section{Figure 6 - Interpretations of the displays}

This figure shows how the respondents interpreted the different display alternatives.

"9a. How do you interpreter this display?

9b. How do you consider the situation for the child sitting in a rear facing child seat in the front seat?

Safe? Unsafe? Do not know?"

\section{The white and light grey}

The respondents that interpreted the display correctly both by ticking the right box and by writing the correct interpretation are represented with white in the diagram.

The respondents that wrote the correct interpretation but perhaps ticked the wrong box are represented with a light grey in the diagram. The reason to group these answers is that some respondents did not answer the question correctly since they ticked the box "unsafe" all through the questionnaire due to skepticism towards the technical system. Furthermore, the respondents that ticked the correct box but did not leave a written answer are also included in this share.

In other words, the display alternative that has the largest share of white and light grey did get the best result.

The dark grey and black

The respondents that were unsure about how to interpret the display alternative are represented with a dark grey.

The respondents that gave an incorrect interpretation or ticked the box "unsafe" without writing anything are represented with black in the diagram.

In other words, the display alternative that has the largest share of dark grey and black did get the poorest result.

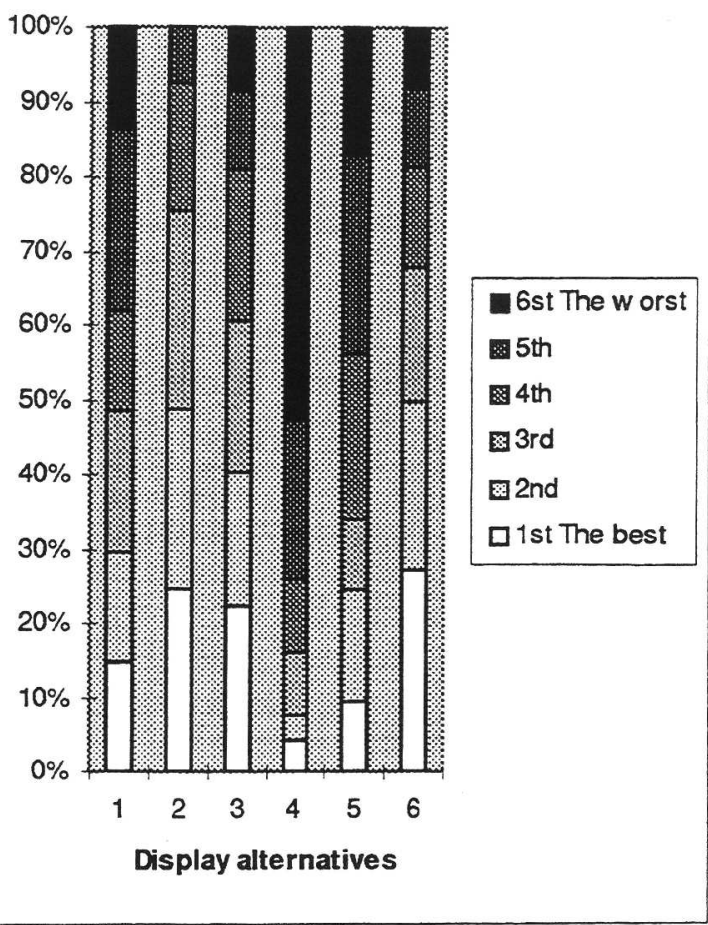

Figure 6 - Interpretations of the displays

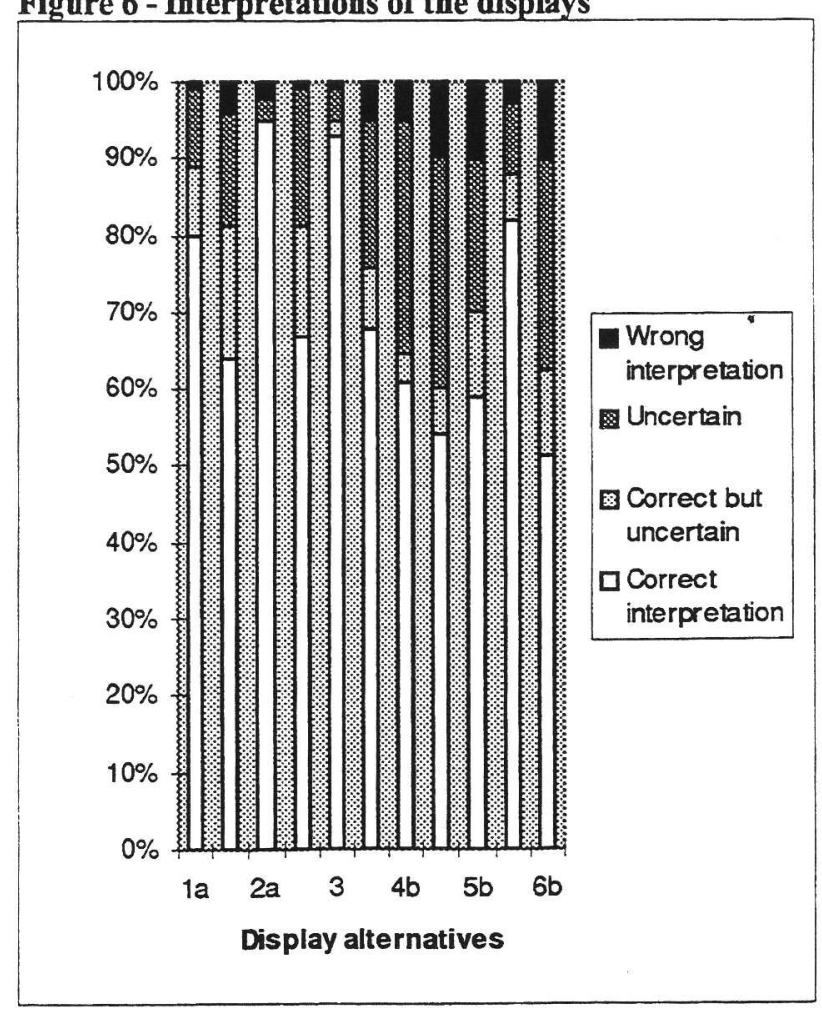


Figure 7- The preferred airbag disconnection system

This figure shows the respondents' attitude towards a different possible technical system.

"17. Would you prefer an automatic sensor system that detects when there is a child placed in the front and then disconnects the airbag?

18. Would you prefer to solely control the airbag by disconnecting and connecting the airbag by i.e. using a key or another control?

19. Would you prefer a combined system, an automatic system with the possibilty to override it manually?"

Figure 8 - The preferred illumination of the display

This figure shows how the respondents would like the display to be illuminated.

"16. How would you like the display to be lit?"
Figure 7- The preferred airbag disconnection system

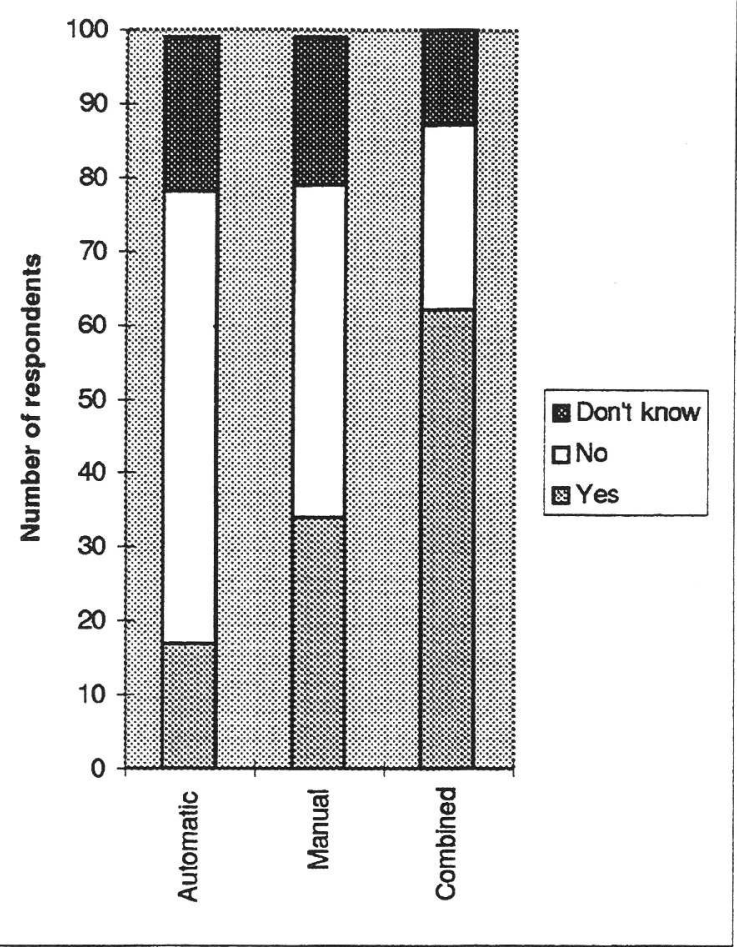

Figure 8 - The preferred illumination of the display

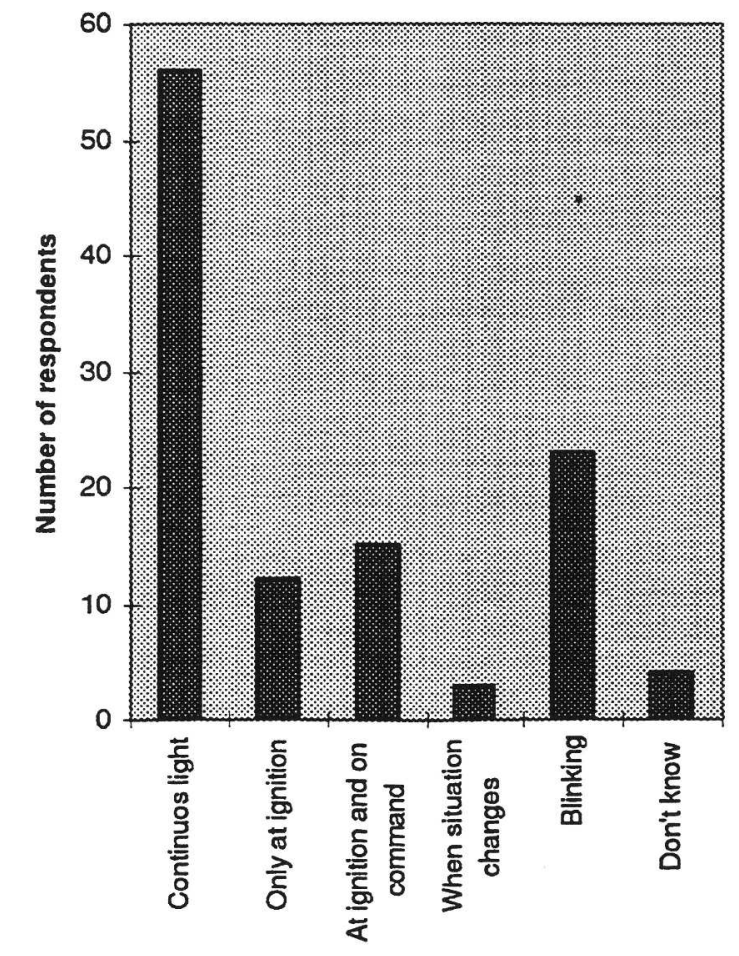




\subsection{Discussion}

\section{The preferred display alternative}

In order to judge which display alternative that is the most preferred both the order of preference, Figure 5, as well as the interpretation diagram, Figure 6 , have to be taken into consideration.

\section{Alternative 1}

The ranking of alternative 1 was average according to Figure 5 (Order of preference), but it does get a rather good result in Figure 6 (Interpretation of the displays).

\section{Alternative 2 and 3 \\ Alternative 2 and 3 both get high ranking results as well as a high degree of correct interpretations. Alternative $2 \mathrm{a}$ and 3 have the same information content and both get a high degree of correct interpretations.}

Alternative $2 \mathrm{~b}$, which shows the safe situation for the child (airbag disconnected), does not get as high degree of correct interpretations as alternative $2 a$, showing when the airbag is connected. Generally, the displays communicating that the airbag is disconnected (safe situation for the child) were more difficult to understand. (See general difficulties).

Compared to the other displays showing that the airbag is disconnected, the number of correct interpretations of $2 b$ is relatively high.

Figure 5 (Order of preference) gives the highest ranking to alternative 2 . This shows that the interviewees would like an information display that communicates both the safe and the dangerous situation for the child.

\section{Alternative 4 \\ From the ranking list as well as from interpretations one could easily judge alternative 4 to be the least desirable. The display is difficult to understand since it does not warn but only shows what should be placed in the front passenger} seat.

An example of an incorrect interpretation of 4a; "There is an airbag installed in the rear seat".

An example of an incorrect interpretation of $4 \mathrm{~b}$; "The airbag is specifically for a child seat".

\section{Alternative 5}

Alternative 5 does get a rather poor result in both Figure 5 and 6.

The respondents find that alternative 5 included too much information and do not understand the meaning of green colour in relation to red.

An example of an incorrect interpretation of 5a; "The airbag is connected but it is OK to place the child there"

An example of an incorrect interpretation of 5b; "Both are safe"

\section{Alternative 6}

Alternative 6 does get a rather high ranking result in Figure 6 (Order of preference). Some comments points out that the text is helpful. Nevertheless the interpretations of $6 \mathrm{~b}$ gave poor results.

An example of an incorrect interpretation of $6 \mathrm{~b}$; "The airbag is disconnected for both the driver and front seat passenger".

\section{General difficulties of interpretation}

Generally the respondents have difficulties interpreting the displays showing that the airbag is disconnected (the safe situation for the child). There are several aspects to consider.

The disconnection of the airbag is a new technical possibility which some respondents might have difficulties in understanding.

It is not obvious to associate the green colour with a safe situation. Unfortunately, in the questionnaire, the green colour was close to a yellow colour. Furthermore, a green or an amber light is usually used to show that a function is switched on. In this case the green light is shown when something is disconnected.

Another general problem is that the text "Passenger airbag" and the text "Off/On" are separate. Some respondents did not understand whether the text "On/Off" related to the symbol or to the text "Passenger airbag".

\section{The preferred airbag disconnection system}

Referring to Figure 7 (The preferred system) it seems like the respondents would prefer a combined system, in other words an automatic system that manually could be overridden.

The system that had the lowest ranking was the automatic system. This might be a consequence of people often being rather suspicious to unfamiliar technical systems.

It should be noticed is that the respondents did not fully trust themselves controlling a manual system.

\section{The preferred illumination}

Referring to Figure 8 (The preferred illumination) most respondents would like the display to be continuously lit. This might reflect the uncertainty among the respondents since they would like to continuously monitor the system.

However, it is probably very difficult for the respondents to judge how the display should be illuminated if it is not shown under realistic conditions. 


\section{CONCLUSIONS}

The following conclusions can be drawn from the study:

- Text - Symbol

The display should be based on a combination of text and symbols.

One displayed symbol at the time is enough.

It is important to integrate the text "PASSENGER

AIRBAG" with the text "ON" or "OFF".

- Child - Passenger

The information should focus on the situation for the child. Those displays that also informed about the situation for the adult passenger were more likely to be misunderstood.

- OK - Warning

The information should focus on the dangerous situation for the child.

The displays that communicated what should not be placed in the front passenger seat were better understood than the displays that communicated what could safely be placed there.

\section{- Colours}

The use of colours magnifies the message. Red is associated with danger but not as a standalone message. To use a red colour in combination with a slash across the symbol gives the best understanding of a warning.

The high understanding of this combination has been shown in other studies. (Bruyes, 1996)

The use of green to communicate a safe situation is not evident.

\section{Display alternative}

Regarding which display alternative that is the most preferred, alternative $\mathbf{2}$ is recommended. Yet it has to be modified. The text "Passenger airbag" and the text "On/Off" has to be integrated in the display.

Nevertheless, it can be discussed whether the green "OK with childseat symbol " has to be included or if it would be enough with the text "Passenger airbag OFF".

\section{Redesigned alternative 2}

\section{PASS. AIFBAGOA}

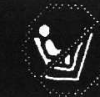

\section{PASS AIRBAG OFF}

\section{Airbag disconnection system}

Regarding which technical system that is the most preferred, the result of this study indicates that an automatic system with the possibility to override it manually would be best accepted.

\section{POST-SCRIPT}

This study has provided some preliminary insight into peoples reactions to airbags and children in the front seat and to displays indicating airbag status. It should be kept in mind, that the study was conducted in Sweden, a country where airbags are not yet a natural ingredient in passenger cars. However, the concern over deactivation systems for airbags are probably universal. It is hoped that this study will contribute to the development of an easily understood and widely used, hopefully internationally standardised, information display for airbag status. A good and clearly understood information display will hopefully eliminate some of the public concern over the potential risks of airbags deploying at the wrong time.

\section{REFERENCES}

- Vision in vehicles, Iconic Information Presentation: Pictograms understanding, study about ambiguity,M.P. Bruyas, 1996

- International standard, ISO 2575:1995(E) 
VI FORSKAR FÖR ETT LIV I RÖRELSE

Statens väg- och transportforskningsinstitut (VTI) har kompetens och laboratorier för kvalificerade forskningsuppdrag inom transporter och samhällsekonomi, trafiksäkerhet, fordon, miljö samt för byggande, drift och underhăll av vägar och järnvägar.

The Swedish National Road and Transport Research Institute (VTI) has laboratories and know-how for advanced research commissions in transport and welfare economics, road safety, vehicles and the environment. It also has research capabilities for the construction, operation and maintenance of roads and railways.

\section{Adress}

Postal address

SE-581 95 Linköping, Sweden
Telefon

Telephone

Nat 013-20 4000

Int +4613204000
Fax

E-post

E-mail

Nat 013-14 1436

Int +4613141436 